\title{
Schwerpunkt: Quo vadis, deutsche Politikwissenschaft?
}

Online publiziert: 6. April 2017

(C) Springer Fachmedien Wiesbaden 2017

Die Welt um uns verändert sich rasant. Ob in der Bundesrepublik, in Europa oder international: Wir leben in turbulenten Zeiten. Insbesondere politisch und gesellschaftlich ist viel im Wandel. Das führt zu Unbehagen und Unsicherheit, nicht nur bei den Bürgerinnen und Bürgern, sondern auch bei den Autoritäten, bei denen die Menschen früher Orientierung suchten: den Parteien, den Kirchen, den Gewerkschaften.

In solchen Zeiten kommt es umso mehr darauf an zu erklären, zu analysieren, Optionen zu diskutieren, Wissen bereitzustellen. Wer könnte das besser als Politikwissenschaftlerinnen und Politikwissenschaftler? Das Know-how hierfür ist zweifellos vorhanden. Doch ist die deutsche Politikwissenschaft ein solcher Orientierungslotse? Ist sie hierzu willens und in der Lage?

Bereits seit geraumer Zeit ist ein intensiver Diskussions- und Austauschprozess über den Stand, die Perspektiven und das Selbstverständnis der deutschen Politikwissenschaft innerhalb des Faches im Gange, der sich durch alle Teildisziplinen und alle Statusgruppen zieht. Wie ist es um die öffentliche Sichtbarkeit und die Ausstrahlung der deutschen Politikwissenschaft bestellt? Welche Auswirkungen haben eine zunehmende Spezialisierung und Internationalisierung auf unsere Disziplin? Welche Folgen hat die Bologna-Reform für die Ausbildung des politikwissenschaftlichen Nachwuchses? Nicht zuletzt: Wie attraktiv ist unser Fach als Arbeitsplatz?

Diese und weitere Überlegungen sollen Ausgangspunkt des folgenden Forums der Zeitschrift für Politikwissenschaft (ZPol) sein. Hierfür haben wir 17 Kolleginnen und Kollegen unterschiedlicher Teildisziplinen, Statusgruppen (Emeriti, ProfessorInnen, Wissenschaftlicher Nachwuchs) und Fachvereinigungen aus Universitäten und politikwissenschaftlichen Instituten verschiedener Größen aus ganz Deutschland danach befragt, wie sich nach ihrer Einschätzung unser Fach in den kommenden fünf Jahren entwickeln wird respektive sollte. Auch die ZPol-Herausgeber haben dazu einen gemeinsamen Beitrag verfasst, der das Forum eröffnet und in die Debatte einführt. 